\title{
Mean platelet volume as a simple marker of repeated coronary artery intervention after off-pump technique (OPCAB) procedures - initial report
}

\author{
Tomasz K. Urbanowicz ${ }^{1}$, Michał Michalak2 ${ }^{2}$, Weronika Mikołajewska ${ }^{3}$, Michał Rodzki ${ }^{1}$, Bartłomiej Perek ${ }^{1}$, \\ Anna Olasińska-Wiśniewska ${ }^{1}$, Michał Bociański ${ }^{1}$, Marek Jemielity ${ }^{1}$ \\ ${ }^{1}$ Cardiac Surgery and Transplantology Department, Poznan University of Medical Sciences, Poznan, Poland \\ ${ }^{2}$ Department of Computer Science and Statistics, Poznan University of Medical Sciences, Poznan, Poland \\ ${ }^{3}$ Poznan University of Medical Sciences, Poznan, Poland
}

Kardiochirurgia i Torakochirurgia Polska 2021; 18 (4): 231-235

\begin{abstract}
Introduction: Mean platelet volume (MPV) is claimed to be a useful marker to predict long-term risk for major adverse cardiac effects (MACE) in patients undergoing percutaneous coronary interventions ( $\mathrm{PCl}$ ).

Aim: To explore the possible dependence on MPV and postoperative $\mathrm{PCI}$ risk in patients with complex coronary artery disease undergoing coronary artery bypass grafting in off-pump technique (OPCAB).

Material and methods: We retrospectively analyzed 236 consecutive patients (180 (76\%) males and 56 (24\%) women) referred for surgery due to complex coronary artery disease between 2015 and 2016 in our department. The mean $5.1 \pm 0.8$ year follow-up included profound analysis of MACE events including acute coronary syndromes and percutaneous interventions.

Results: The $5 \pm 1$ year follow-up was completed by 213 (90\%) patients with 2 (1\%) deaths within the first year after surgery. In logistic univariate and multivariate model regression analysis two parameters were found significant, i.e. preoperative white blood cells and postoperative MVP, for PCI risk in long-term follow-up. The odds ratio values for postoperative MPV were 1.78 $(95 \% \mathrm{Cl}, p=0.0036)$ and $1.76(95 \% \mathrm{Cl}, p=0.005)$ in univariate and multivariate models with cutoff point $>8.7$, sensitivity $45.65 \%$, specificity $78.72 \%$.

Conclusions: MPV can be regarded as a simple marker of PCI risk following OPCAB procedures. The preoperative MPV indicates the individual tendency for worse prognosis more than procedure dependence.
\end{abstract}

Key words: off-pump coronary artery bypass, mean platelet volume, major adverse cardiac events, white blood cells.

\section{Introduction}

Platelets are one of the main goals in coronary artery disease treatment. The simple parameters are helpful in evaluation of platelet function and activity. Platelet size presented as mean platelet volume (MPV) and mean platelet volume to platelet count (PLT) ratio (MPV/PLT ratio) have been reported as useful markers of long-term risk prediction for major adverse cardiac effects (MACE), including myocardial infarction and stroke, in patients undergoing percutaneous coronary interventions ( $\mathrm{PCI}$ ) [1]. Previous reports in a multivariable analysis presented an association between MPV/PLT and mortality following PCl in non-ST elevated myocardial infarction (NSTEMI) patients [2].

Aim

The aim of the study was to analyze the correlation between pre-operative and post-operative MPV and post- operative $\mathrm{PCl}$ risk in patients with complex coronary artery disease undergoing coronary artery bypass grafting in offpump technique (OPCAB).

\section{Material and methods}

We retrospectively analyzed 236 consecutive patients (180 (76\%) males and 56 (24\%) women) referred for cardiac surgery to our department due to complex/diffuse coronary artery disease in the period 2015-2016. Patients were qualified for surgery based on coronary angiography results, with 79 (33\%) of them presenting left main (LM) disease. The concomitant diseases included arterial hypertension in 170 (72\%), diabetes mellitus in 79 (33\%) and hypercholesterolemia in 128 (54\%). Demographic and clinical data are outlined in Table I.

The follow-up (mean: $5.1 \pm 0.8$ years) included precise analysis of requirement for percutaneous interventions.

Address for correspondence: Dr Tomasz K. Urbanowicz, Cardiac Surgery and Transplantology Department, Poznan University of Medical Sciences, Poznan, Poland, phone: +48 61854 9233, e-mail: tomasz.urbanowicz@skpp.edu.pl

Received: 15.07.2021, accepted: 26.09.2021. 
Table I. Demographic and clinical data

\begin{tabular}{|c|c|c|c|}
\hline Parameter & $\begin{array}{c}\text { Group } 1 \\
\mathrm{PCl} \text { free group }(n=189)\end{array}$ & $\begin{array}{c}\text { Group2 } \\
\mathrm{PCl} \text { group }(n=47)\end{array}$ & $P$-value \\
\hline Gender & $146(77 \%) / 43(23 \%)$ & 37 (79\%)/10 (21\%) & 0.9828 \\
\hline Age & $64 \pm 8$ & $65 \pm 9$ & 0.4554 \\
\hline \multicolumn{4}{|l|}{ Concomitant diseases: } \\
\hline Arterial hypertension & 135 (71\%) & 36 (77\%) & 0.4113 \\
\hline COPD & $18(10 \%)$ & $6(13 \%)$ & 0.5499 \\
\hline $\mathrm{DM}$ & $54(29 \%)$ & $9(19 \%)$ & 0.1670 \\
\hline Stroke & $11(6 \%)$ & $4(10 \%)$ & 0.3295 \\
\hline Hypercholesterolemia & $101(53 \%)$ & $29(62 \%)$ & 0.2672 \\
\hline PAD & $24(13 \%)$ & $10(21 \%)$ & 0.1645 \\
\hline \multicolumn{4}{|l|}{ Surgical indication: } \\
\hline$\underline{L M}$ disease & $50(27 \%)$ & $14(30 \%)$ & 0.6805 \\
\hline 3-vessel disease & $110(58 \%)$ & $23(49 \%)$ & 0.2657 \\
\hline 2-vessel disease & 29 (15\%) & $10(21 \%)$ & 0.3177 \\
\hline \multicolumn{4}{|l|}{ Echocardiographic results: } \\
\hline LV diameter [mm] & $49 \pm 7$ & $50 \pm 7$ & 0.3817 \\
\hline LVEF & $53 \pm 9$ & $51 \pm 10$ & 0.1839 \\
\hline \multicolumn{4}{|l|}{ Surgery: } \\
\hline Overall time [min] & $145 \pm 42$ & $139 \pm 39$ & 0.3762 \\
\hline Mean anastomosis & $2.4 \pm 0.6$ & $2.3 \pm 0.7$ & 0.3241 \\
\hline $\begin{array}{l}\text { Hospitalization time [days] } \\
\text { (Excluding in hospital mortality) }\end{array}$ & $8.8 \pm 3$ & $\begin{array}{c}12 \pm 8 \\
(10 \pm 4)\end{array}$ & $\begin{array}{l}0.0096 \\
0.0589\end{array}$ \\
\hline
\end{tabular}

COPD - chronic obstructive pulmonary disease, DM - diabetes mellitus, LV - left ventricle, LVEF - left ventricle ejection fraction, PAD - peripheral artery disease.

Patients were divided into two groups regarding the need for reinterventions in previously revascularized arteries by $\mathrm{PCl}$ intervention. Demographic and clinical data are outlined in Table I.

On the day of admission, blood samples for complete blood count and biochemical tests were collected. The blood samples were also collected 24 hours following surgery and on discharge.

All patients signed written informed consent for routine surgery for coronary artery disease (CAD). Blood samples' analysis and blood flow measurements were performed with standard of care. The study received positive agreement of the Local Ethics Committee.

All the procedures were performed via complete median sternotomy without cardiopulmonary bypass as OPCAB technique. A deep pericardial stitch was routinely used to elevate the beating heart and tissue stabilizer (Octopus III, Medtronic, USA) to immobilize segment of the recipient coronary artery. After coronary artery longitudinal incision, intraluminal shunts (Medtronic, USA) were applied, and the anastomoses were performed with a continuous monofilament 7-0 suture. The standard anastomosis of the left mammary artery to the left descending artery was performed in 222 (93\%) patients and to the diagonal branch in 2 more (1\%) and the right mammary artery to the left descending artery was applied in 14 more (6\%). The left descending artery was anastomosed to the circumflex artery in 14 (6\%) patients. The radial artery was anastomosed to the right coronary artery in 10 (4\%). The venous grafts were anasto- mosed to the circumflex artery in 187 (79\%) patients and to the right coronary artery in 92 (39\%) more.

Following the surgery, all patients were transferred to the postoperative intensive care unit (ICU). Electrocardiography (ECG) and invasive monitoring of vital functions, including arterial blood pressure (ABP), were carried out immediately upon their admission. Upon discharge, all patients were referred to the outpatient clinic follow-up.

\section{Data collection}

The data were collected from initial hospitalization followed by regular follow-ups in the outpatient clinic and telephone questionnaire. The exclusion criteria included patients with acute coronary syndromes referred for surgery or presenting with bone marrow diseases (hematologic), chronic inflammatory diseases and history of oncologic disease.

Laboratory results were obtained at three time intervals including samples collected on admission, on the first postoperative day and on discharge. Perioperative laboratory results are presented in Table II.

We scrupulously collected the postoperative mid-term results including survival rate, clinical status, and risk for major adverse events.

\section{Statistical analysis}

Continuous variables are reported as mean \pm standard deviation (SD) when data followed a normal distribution; otherwise, the data were presented as medians and in- 
terquartile range $\left[\mathrm{Q}_{1}-\mathrm{Q}_{3}\right]$, where $\mathrm{Q}_{1}$ is lower and $\mathrm{Q}_{3}$ upper quartile, respectively. The differences between groups were calculated by means of unpaired Student's $t$-test (normally distributed) or the Mann-Whitney test. Categorical variables were reported as numbers $(n)$ with percentages (\%) and then compared by the test for proportions. The receiver operating characteristic (ROC) curve was used to find potential predictors of MACE. The optimal cut-off values were presented according to the highest sensitivity and specificity denoted by Youden's index. A logistic regression model was used to find potential risk factors of MACE. The result was presented as odds ratios (OR) and corresponding 95\% confidence intervals. All tests were considered significant at $p<0.05$. The analysis was performed using MedCalc Statistical Software version 19.6 (MedCalc Software Ltd, Ostend, Belgium; https://www.medcalc.org; 2020).

\section{Results}

\section{Clinical outcomes}

The study group included 236 consecutive patients who underwent off-pump coronary artery bypass grafting in our institution between 2015 and 2016.

During in-hospital stay 1 (0.5\%) patient died, and 5 (2\%) required reintervention due to excessive bleeding.

In the early post-operative period 50 (21\%) subjects developed atrial fibrillation, acute kidney injury was noted in $5(2.1 \%)$ cases and one of them $(0.5 \%)$ required de novo temporary renal replacement therapy.

The mean in-hospital stay of survivors was $9.1 \pm 4.1$ days. The $5 \pm 1$ year follow-up was completed by 213 (90\%) patients with 2 (1\%) deaths within the first year after surgery. During the 5-year observation period, $23(10 \%) \mathrm{PCl}$ interventions were documented including 12 (5\%) in the course of acute myocardial infarctions (MI) episodes. The interventions involved previously revascularized coronary arteries.

All laboratory parameters obtained preoperatively, on the $1^{\text {st }}$ and $7^{\text {th }}$ postoperative day presented in Table II including white blood cells (WBC), lymphocyte count, hemoglobin ( $\mathrm{Hb}$ ), platelets (PLT), MPV, MPV/PLT, serum creatinine and troponin were included in the analysis.

In logistic univariate and multivariate model regression analysis two parameters were found significant, i.e. preoperative $\mathrm{WBC}$ and postoperative $\mathrm{MVP}$, for $\mathrm{PCl}$ risk in longterm follow-up. The OR values for preoperative WBC were $0.84(95 \% \mathrm{Cl}, p=0.0313)$ and $0.83(95 \% \mathrm{Cl}, p=0.0352)$ in univariate and multivariate models with cutoff point $\leq 8.9$, sensitivity $85.11 \%$, specificity $32.80 \%$. The OR values for postoperative MPV were $1.78(95 \% \mathrm{Cl}, p=0.0036)$ and $1.76(95 \% \mathrm{Cl}, p=0.005)$ in univariate and multivariate mod-
Table II. Perioperative laboratory results

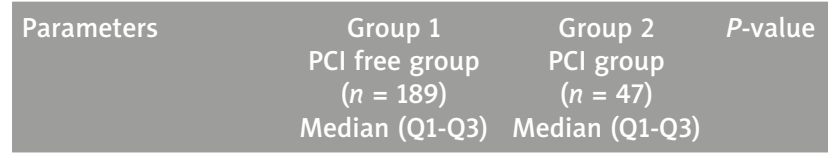

Preoperative:

\begin{tabular}{lccc}
\hline WBC & $7.9(6.4-9.4)$ & $7.4(6-8.6)$ & 0.0344 \\
\hline Lymphocytes & $1.97(1.5-2.3)$ & $1.6(1.3-2.0)$ & 0.4041 \\
\hline $\mathrm{Hb}$ & $8.6(8.1-9.3)$ & $8.6(8.1-9.3)$ & 0.7052 \\
\hline $\mathrm{PLT}$ & $233(196-273)$ & $230(193-252)$ & 0.2673 \\
\hline $\mathrm{MPV}$ & $8.7(8.2-9.3)$ & $8.5(7.8-9.3)$ & 0.0710 \\
\hline MPV/PLT & $0.04(0.03-0.05)$ & $0.04(0.03-0.05)$ & 0.9826 \\
\hline Serum creatinine & $89(76-102)$ & $89(79-108)$ & 0.6073 \\
\hline
\end{tabular}

Postoperative $1^{\text {st }}$ day:

\begin{tabular}{lccc}
\hline WBC & $13.3(11-16.1)$ & $14.3(11.2-17.6)$ & 0.2691 \\
\hline Lymphocytes & $1.06(0.8-1.3)$ & $0.9(0.7-1.2)$ & 0.1021 \\
\hline $\mathrm{Hb}$ & $7.2(6.8-7.8)$ & $7.5(7-7.8)$ & 0.2202 \\
\hline $\mathrm{PLT}$ & $210(173-248)$ & $195(164-227)$ & 0.0916 \\
\hline MPV & $8.9(8.4-9.5)$ & $9(8.5-9.5)$ & 0.9075 \\
\hline MPV/PLT & $0.04(0.04-0.05)$ & $0.05(0.04-0.06)$ & 0.1392 \\
\hline Troponin & $1.6(0.8-3.3)$ & $1.6(0.6-4.9)$ & 0.7352 \\
\hline Serum creatinine & $97(82-117)$ & $99(80-123)$ & 0.6441 \\
\hline
\end{tabular}

Postoperative $7^{\text {th }}$ day:

\begin{tabular}{lccc}
\hline WBC & $8.8 \pm 2.6$ & $8.5(7-10.2)$ & 0.9971 \\
\hline Lymphocyte & $2.2 \pm 1.4$ & $2(1.6-2.4)$ & 0.0280 \\
\hline $\mathrm{Hb}$ & $6.9 \pm 0.8$ & $6.9(6.5-7.3)$ & 0.3100 \\
\hline $\mathrm{PLT}$ & $280 \pm 99$ & $268(224-341)$ & 0.2779 \\
\hline MPV & $8.3 \pm 0.8$ & $8.3(7.8-8.7)$ & 0.0048 \\
\hline MPV/PLT & $0.08 \pm 0.2$ & $0.03(0.02-0.04)$ & 0.1424 \\
\hline Serum creatinine & $90 \pm 29$ & $86(73-99.6)$ & 0.6532 \\
\hline
\end{tabular}

$\mathrm{Hb}$ - hemoglobin, MPV - mean platelet volume, MPV/PLT - mean platelet volume/ mean platelet volume, PLT - platelets, WBC - white blood count.

els with cutoff point $>8.7$, sensitivity $45.65 \%$, specificity 78.72\% (Table III, Figures 1, 2).

\section{Discussion}

Our study results present, for the first time to the best of our knowledge, the relationship between risk of postoperative mid-term MACE and MPV and MPV/PLT obtained on the $7^{\text {th }}$ postoperative day in OPCAB patients as possible predictive factors. The MPV and MPV/PLT on the $7^{\text {th }}$ postoperative day showed a positive correlation with 5 -year risk for percutaneous coronary intervention in our study.

Table III. Logistic regression analysis results

\begin{tabular}{lcccc} 
Parameters & $\begin{array}{c}\text { Univariate model } \\
\text { OR }(95 \% \mathrm{Cl})\end{array}$ & P-value & $\begin{array}{c}\text { Multivariate model } \\
\text { OR }(95 \% \mathrm{Cl})\end{array}$ & $\begin{array}{c}\text { P-value } \\
\text { Preoperative WBC }\end{array}$ \\
\hline Postoperative $7^{\text {th }}$ day - MPV & $0.84(0.71-0.98)$ & 0.0313 & $0.83(0.70-0.98)$ & 0.0352 \\
\hline
\end{tabular}

MPV - mean platelet volume, WBC - white blood count 


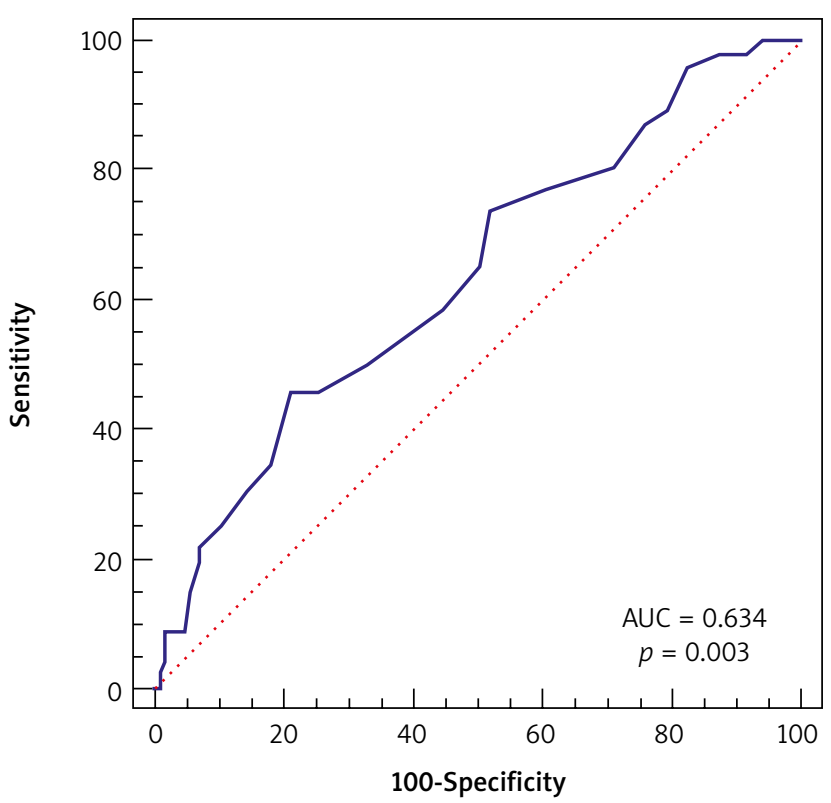

Figure 1. Receiver operating characteristics curves for postoperative MPV ( $7^{\text {th }}$ day). Cut-off point $>8.7$ with sensitivity $=45.65 \%$ and specificity $=78.72 \%$

Platelets play a significant role not only in chronic coronary processes including development of atherosclerotic lesions but also in the acute phase as plaque destabilization and atherothrombosis [3]. Various platelet indices are used to measure metabolic, structural, and morphological parameters including its size. In our study we focused on MPV and its ratio to PLT count (MVP/PLT) as indicators of young platelets' increase in circulation. Young platelets are more active and have a higher propensity for adhesion and aggregation [4]. MPV and the even more accurate MPV/ PLT may be regarded as platelet reactivity markers that are associated with worse prognosis in patients with non-STsegment elevation myocardial infarction [5].

In previous studies, the association between platelet functions and risk of adverse events in various types of coronary artery disease was postulated [6].

We believe there is a need for a simpler marker that can reflect the platelets' activity or function as available tests are expensive and used mostly for research purposes [7]. Younger platelets, as we mentioned before, are larger and contain more alpha granules compounded with higher expression of adhesion receptors [8]. The platelet life circle includes 10-11 days within 5 days circulation time. It takes up to 5 days to clear the circulating pool from previous platelets and remove them completely. Therefore, results obtained from the $7^{\text {th }}$ day include only newly produced platelets.

Moreover, during surgical revascularization the reperfusion phenomenon which activates the inflammatory reaction may increase young platelets' release from bone marrow within 24-32 hours following surgery [9]. The link between inflammation and release of young platelets was presented by Gasparyan [10].

Tian et al. confirmed again that high MPV was an independent predictor of adverse prognosis for patients under-

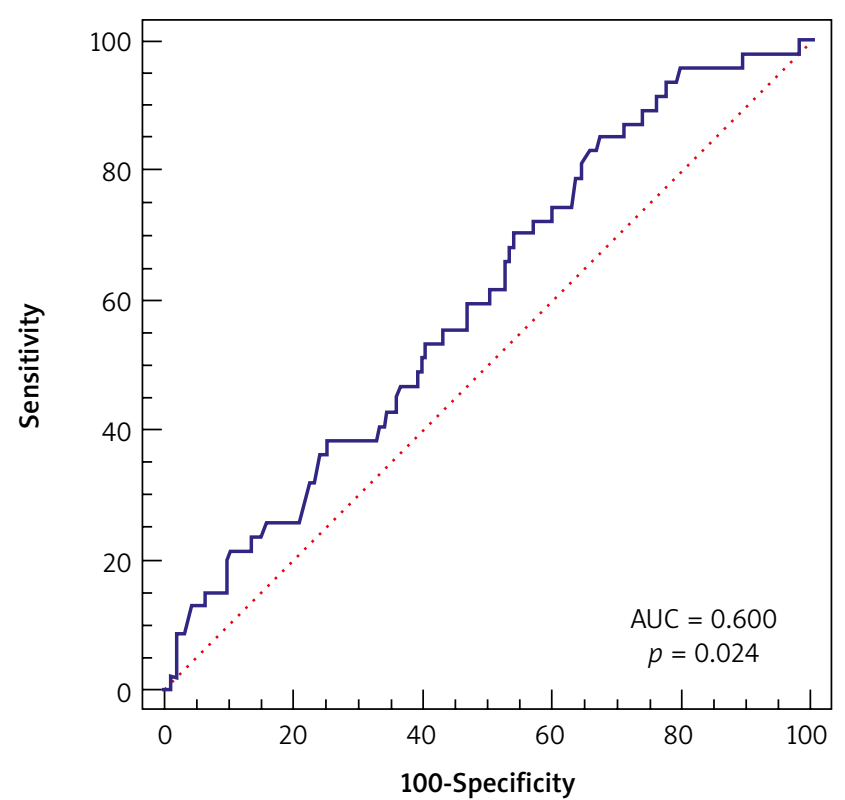

Figure 2. Receiver operating characteristics curves for preoperative WBC. Cut-off point $<=8.9$ with sensitivity $=85.11 \%$ and specificity $=32.80 \%$

going PCI with ST-segment elevated MI [11]. Huczek et al. proved that MPV is a strong predictor of impaired angiographic reperfusion including 6-month mortality [12]. Shah et al. in his analysis detected a strong association between increase in MPV over time following PCl and long-term results [13]. Our data suggest that postoperative MPV and its ratio to PLT count (MPV/PLT) can be considered in evaluation of OPCAB patients' prognosis. The percutaneous interventions following the surgical procedures involved arteries surgically treated with venous grafts.

Our results present the correlation between preoperative WBC and need for future $\mathrm{PCl}$ in accordance with previous studies relating WBC with increased risk for cardiovascular disease [14]. In WBC the uncertainty remains which leukocyte subtypes carry this risk, explaining our conservative approach to the presented parameter [15].

Gunday et al. pointed out platelet mass index (PMI) as a valuable inflammatory indicator in comparison between on-pump and off-pump technique [16]. In the available literature, there is no publication referring to MPV changes in OPCAB patients, although MPV changes in on-pump revascularization related to cardiopulmonary bypass institution has already been postulated [17].

The present results support worse patency of venous grafts as they were the target arteries for $\mathrm{PCl}$ interventions. There were no interventions in coronary arteries supplied by arterial grafts. The MPV can be regarded as a possible marker of venous graft occlusion.

The present study has several limitations. First, it is retrospective. Second, it is a single-center study limited to over 200 cases. Third, it is related to stable complex coronary disease. We believe a wider cohort of patients, preferably including multicenter research, is necessary for further investigation. 
The study was not supported by any grants, nor were any funds obtained.

\section{Conclusions}

MPV can be regarded as a simple marker of $\mathrm{PCI}$ risk following OPCAB procedures. The preoperative MPV indicates the individual tendency for worse prognosis more than procedure dependence.

\section{Disclosure}

The authors report no conflict of interest.

\section{References}

1. Yu T, Dong Y, Sun Z, Sun Z. Comparison of prognostic significance of mean platelet volume/platelet count with GRACE for long-term prognosis in patients with non-ST-segment elevation myocardial infarction undergoing percutaneous coronary intervention. Int J Cardiol 2017; 228: 335-340.

2. Azab B, Torbey E, Singh J, Akerman M, Khoueiry G, McGinn JT, Widmann WD, Lafferty J. Mean platelet volume/platelet count ratio as a predictor of longterm mortality after non-ST-elevation myocardial infarction. Platelets 2011; 22: 557-566.

3. Shah B, Oberweis B, Tummala L, Amoroso NS, Lobach I, Sedlis SP, Grossi E, Berger JS. Mean platelet volume and long-term mortality in patients undergoing percutaneous coronary intervention. Am J Cardiol 2013; 111: 185-189.

4. Pereg D, Berlin T, Mosseri M. Mean platelet volume on admission correlates with impaired response to thrombolysis in patients with ST-elevation myocardial infarction. Platelets 2010; 21: 117-121.

5. Taglieri N, Saia F, Rapezzi C, Marrozzini C, Bacchi Reggiani ML, Palmerini T, Ortolani P, Melandri G, Rosmini S, Cinti L, Alessi L, Vagnarelli F, Villani C, Branzi A, Marzocchi A. Prognostic significance of mean platelet volume on admission in an unselected cohort of patients with non-ST-segment elevation acute coronary syndrome. Thromb Haemost 2011; 106: 132-140.

6. Sansanayudh N, Anothaisintawee T, Muntham D, McEvoy M, Attia J, Thakkinstian A. Mean platelet volume and coronary artery disease: a systematic review and meta-analysis. Int J Cardiol 2014; 175: 433-440.
7. Breet NJ, van Werkum JW, Bouman HJ, Kelder JC, Ruven HJ, Bal ET, Deneer VH, Harmsze AM, van der Heyden JA, Rensing BJ, Suttorp MJ, Hackeng $\mathrm{CM}$, ten Berg JM. Comparison of platelet function tests in predicting clinical outcome in patients undergoing coronary stent implantation. JAMA 2010; 303: 754-762.

8. Martin JF, Trowbridge EA, Salmon G, Plumb J. The biological significance of platelet volume: its relationship to bleeding time, platelet thromboxane B2 production and megakaryocyte nuclear DNA concentration. Thromb Res 1983; 32: 443-460.

9. Yamamoto M, Nishimori H, Fukutomi T, Yamaguchi T, Orihashi K. Dynamics of oxidative stress evoked by myocardial ischemia reperfusion after off-pump coronary artery bypass grafting elucidated by bilirubin oxidation. Circ J 2017; 81: 1678-1685.

10. Gasparyan AY, Ayvazyan L, Mikhailidis DP, Kitas GD. Mean platelet volume: a link between thrombosis and inflammation? Curr Pharm Des 2011; 17: 47-58

11. Tian C, Song J, He D, Wu J, Sun Z, Sun Z. Predictive value of mean platelet volume/platelet count for prognosis in acute myocardial infarction. Int Heart J 2018; 59: 286-292.

12. Huczek Z, Kochman J, Filipiak KJ, Horszczaruk GJ, Grabowski M, Piatkowski R, Wilczynska J, Zielinski A, Meier B, Opolski G. Mean platelet volume on admission predicts impaired reperfusion and long-term mortality in acute myocardial infarction treated with primary percutaneous coronary intervention. J Am Coll Cardiol 2005; 46: 284-290.

13. Shah B, Oberweis B, Tummala L, Amoroso NS, Lobach I, Sedlis SP, Grossi E, Berger IS. Mean platelet volume and long-term mortality in patients undergoing percutaneous coronary intervention. Am J Cardiol 2013; 111: 185-189.

14. Kim JH, Lim S, Park KS, Jang HC, Choi SH. Total and differential WBC counts are related with coronary artery atherosclerosis and increase the risk for cardiovascular disease in Koreans. PLoS One 2017; 12: e0180332.

15. Horne BD, Anderson JL, John JM, Weaver A, Bair TL, Jensen KR, Renlund DG, Muhlestein JB; Intermountain Heart Collaborative Study Group. Which white blood cell subtypes predict increased cardiovascular risk? J Am Coll Cardiol 2005; 45: 1638-1643.

16. Günday $M$, Çiftçi Ö. Comparison of platelet mass index in on-pump and offpump coronary artery bypass surgery. Heart Surg Forum 2020; 23: E154-E159.

17. Slavka G, Perkmann T, Haslacher H, Greisenegger S, Marsik C, Wagner OF, Endler G. Mean platelet volume may represent a predictive parameter for overall vascular mortality and ischemic heart disease. Arterioscler Thromb Vasc Biol 2011; 31: 1215-1218. 